\title{
Wavelike Structures in the Turbulent Layer During the Morning Development of Convection at Dome C, Antarctica
}

\author{
Igor Petenko $^{1,2}$. Stefania Argentini ${ }^{1}$ - Giampietro Casasanta ${ }^{1}$. \\ Margarita Kallistratova ${ }^{2} \cdot$ Roberto Sozzi $^{1,3} \cdot$ Angelo Viola $^{1}$
}

Received: 3 August 2015 / Accepted: 24 May 2016 / Published online: 22 June 2016

(C) The Author(s) 2016. This article is published with open access at Springerlink.com

\begin{abstract}
In the period January-February 2014, observations were made at the Concordia station, Dome C, Antarctica to study atmospheric turbulence in the boundary layer using a high-resolution sodar. The turbulence structure was observed beginning from the lowest height of about $2 \mathrm{~m}$, with a vertical resolution of less than $2 \mathrm{~m}$. Typical patterns of the diurnal evolution of the spatio-temporal structure of turbulence detected by the sodar are analyzed. Here, we focus on the wavelike processes observed within the transition period from stable to unstable stratification occurring in the morning hours. Thanks to the high-resolution sodar measurements during the development of the convection near the surface, clear undulations were detected in the overlying turbulent layer for a significant part of the time. The wavelike pattern exhibits a regular braid structure, with undulations associated with internal gravity waves attributed to Kelvin-Helmholtz shear instability. The main spatial and temporal scales of the wavelike structures were determined, with predominant periodicity of the observed wavy patterns estimated to be $40-50 \mathrm{~s}$. The horizontal scales roughly estimated using Taylor's frozen turbulence hypothesis are about 250-350 m.
\end{abstract}

Keywords Dome C Antarctica $\cdot$ Kelvin-Helmholtz instability $\cdot$ Morning evolution of the boundary layer $\cdot$ Sodar $\cdot$ Temperature structure parameter

\section{Introduction}

Experimental investigation of internal shear-induced waves due to a Kelvin-Helmholtz (KH) instability is an important problem in the study and parametrization of the stably-stratified

\footnotetext{
Igor Petenko

i.petenko@isac.cnr.it

1 Institute of Atmospheric Sciences and Climate, CNR, Via Fosso del Cavaliere 100, 00133 Roma, Italy

2 A.M. Obukhov Institute of Atmospheric Physics, RAS, Pyzhevskiy 3, Moscow, Russia 119017

3 Regional Environmental Protection Agency of Lazio, Via Boncompagni 101, 00187 Roma, Italy
} 


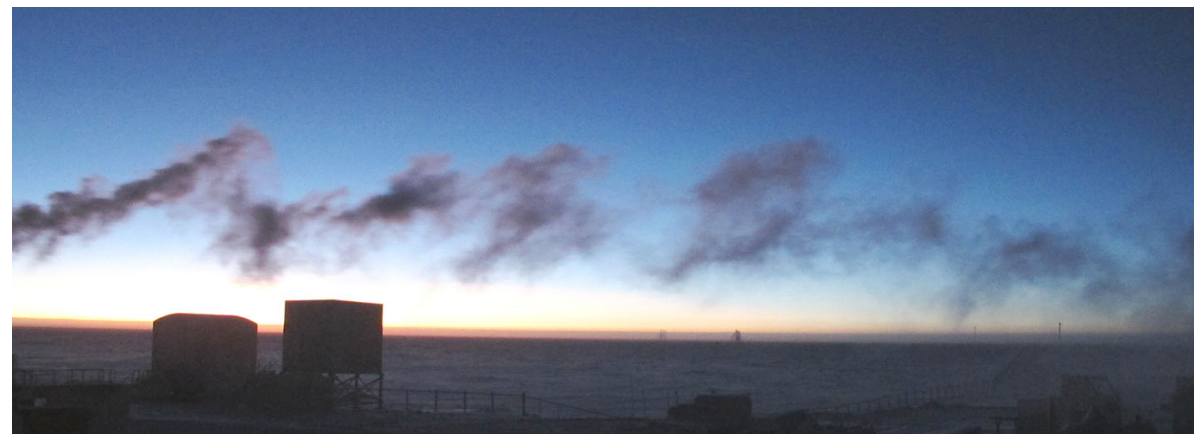

Fig. 1 A smoke flow from the Concordia power station, which shows the wavy structure

atmospheric boundary layer (ABL). It is now generally recognized that peculiarities of the stable ABL, including wave activity, affect not only regional weather, but also the general circulation of the atmosphere (see, e.g. Zilitinkevich and Esau 2003; Esau and Zilitinkevich 2010; Holtslag et al. 2013; McGrath-Spangler et al. 2015). A poor understanding of the exchange processes in the stable ABL and difficulties in its parametrization inhibit the development of numerical modelling of regional and local weather (Mahrt 1998; Cohen et al. 2015). The breakdown of KH billows is considered to be the main mechanism of turbulence excitation in the stable ABL (Patterson et al. 2006; Venkatesh et al. 2014). Interest in KH waves in Antarctica is linked, first of all, to their role in the exchange processes over the ice and snow surface, under conditions of long-lived inversions (Neff et al. 2008; Argentini et al. 2014).

Sodars often provide a clear representation of wavelike structures appearing as layers of enhanced turbulence oscillating in the vertical plane (e.g., Brown and Hall 1978). The duration of the wavy patterns varies from a few minutes to several hours, appearing as billows, braids or cat's eye patterns in radar, sodar and lidar echograms, and cloud photos. Eymard and Weill (1979) observed oscillations resembling regular herringbones [similar to braids in the classification by Gossard and Hooke (1975)] at nighttime with a wave period of about 2 min. A similar herringbone pattern attributed to the $\mathrm{KH}$ instability was observed by Neff et al. (2008) at the South Pole. A few episodes of larger-scale undulations of several minutes in Antarctica were observed by Kouznetsov (2009) and Kouznetsov and Lyulyukin (2014), and examples of small-scale wavy structures with periods of $<1$ min were presented by Petenko et al. (2013) and Argentini et al. (2014). During the sodar measurements at Dome C, observations of the smoke flow from the chimney of the Concordia power station sometimes showed a wavelike pattern (Fig. 1) similar to that shown by the sodar.

The internal structure of an inversion layer capping a convective ABL was observed by Browning (1971), Browning et al. (1973a) and Readings et al. (1973) using pulsed Doppler radar, tethered balloon and radiosonde ascents. They showed how convective circulations in the ABL perturb the height of an inversion, thereby producing undulations of the entire inversion layer. Readings et al. (1973) also hypothesised the possibility of the presence of trapped gravity waves within an inversion. Air motions within $\mathrm{KH}$ billows at a height of $\approx 7 \mathrm{~km}$ were investigated by Browning et al. (1973b) using radar, aircraft and radiosonde measurements. Undulations of an inversion layer overlying convection during the morning hours were also observed by means of a sodar by Taconet and Weill (1983), with periods of $5-7$ min. 
The composite shape and structure of KH billows observed with a sodar was analyzed by Lyulyukin et al. (2013), and in Lyulyukin et al. (2015) a climatology of wavelike structures in the stable ABL and a comprehensive bibliography were presented. However, the climatological data on the occurrence of wavelike structures observed with conventional sodars are not very accurate, since these measurement systems are unable to detect the fine shortlived wavelike turbulent patterns with periods of a few tens of seconds. This leads to the underestimation of the role of the wave processes in the energy transfer in the lower ABL.

A deeper insight into atmospheric processes in the ABL is possible with the use of advanced high-resolution sodars (Neff et al. 2008; Argentini et al. 2012). New features of the surface-based turbulent layer were shown during the one-year experiment conducted at the Concordia station (Dome C, Antarctica) in 2012 (Petenko et al. 2013, 2014a; Argentini et al. 2014). A second long-term experiment using this sodar was made in 2014 at the same site investigating the diurnal behaviour of thermal turbulence in the ABL. In previous studies, it was shown that the diurnal cycle at Dome C during the summer season includes a "night" part, with the stably stratified shallow ABL, and a "day" part. During the "day" part, convective activity develops under the capping inversion layer that reaches heights of 100-300 m (Argentini et al. 2005; Casasanta et al. 2014). "Night" and "day" are quoted because the sun is always above the horizon during the polar summer (from the end of October to the end of February). The presence of a distinct diurnal cycle differentiates the Dome $\mathrm{C}$ site from other well-investigated sites in Antarctica, such as the South Pole and Halley, where the daily cycle during the summer is absent (King et al. 2006; Neff et al. 2008).

From visual inspection of the echograms obtained with conventional sodars, the morning evolution of the ABL presents a gradual ascent of the inversion layer with enhanced turbulence, under which convective plumes expand and rise. A quite surprising internal structure appears in the high-resolution sodar echograms with an extended time scale. Clear wavelike braid patterns with periods of several tens of seconds are observed within the elevated turbulent layer above the convective plumes rising from the surface.

Here, we analyze the characteristics of wavelike structures within an overlying turbulent inversion layer observed by sodar during the morning development of convection near the surface at Dome C in summer January-February 2014. A description of the experimental set-up and the meteorological conditions are given in Sect. 2. In Sect. 3, the characteristics of the diurnal variation of the spatial and temporal structure of turbulence in the ABL, and clear examples of undulation processes are presented. Periods, wavelengths, and vertical extension of the wavy patterns were estimated by visual and spectral analysis. A summary is presented in Sect. 4.

\section{Experimental Set-up and Meteorological Conditions}

\subsection{Site Location and Characterisation}

Concordia station is located at Dome Charlie (Dome C), Antarctic plateau, $900 \mathrm{~km}$ inland from the nearest coast $\left(75^{\circ} 06^{\prime} \mathrm{S}, 123^{\circ} 21^{\prime} \mathrm{E}, 3233 \mathrm{~m}\right.$ a.s.1.) with a surface slope $\approx 0.1 \%$. Its position is shown on the geographical map in Fig. 2. The Sun culminates at $38^{\circ}$ on 21 December, with the weather in summer dominated by the alternation of a surface-based temperature inversion layer and a weak convective ABL capped by an elevated inversion layer. Episodic synoptic perturbations, due to maritime air intrusions produce wind speeds of up to $10 \mathrm{~m} \mathrm{~s}^{-1}$, significantly higher temperatures (up to $-20^{\circ} \mathrm{C}$ ) and dense cloudiness (e.g. Argentini et al. 2001; Genthon et al. 2013). 


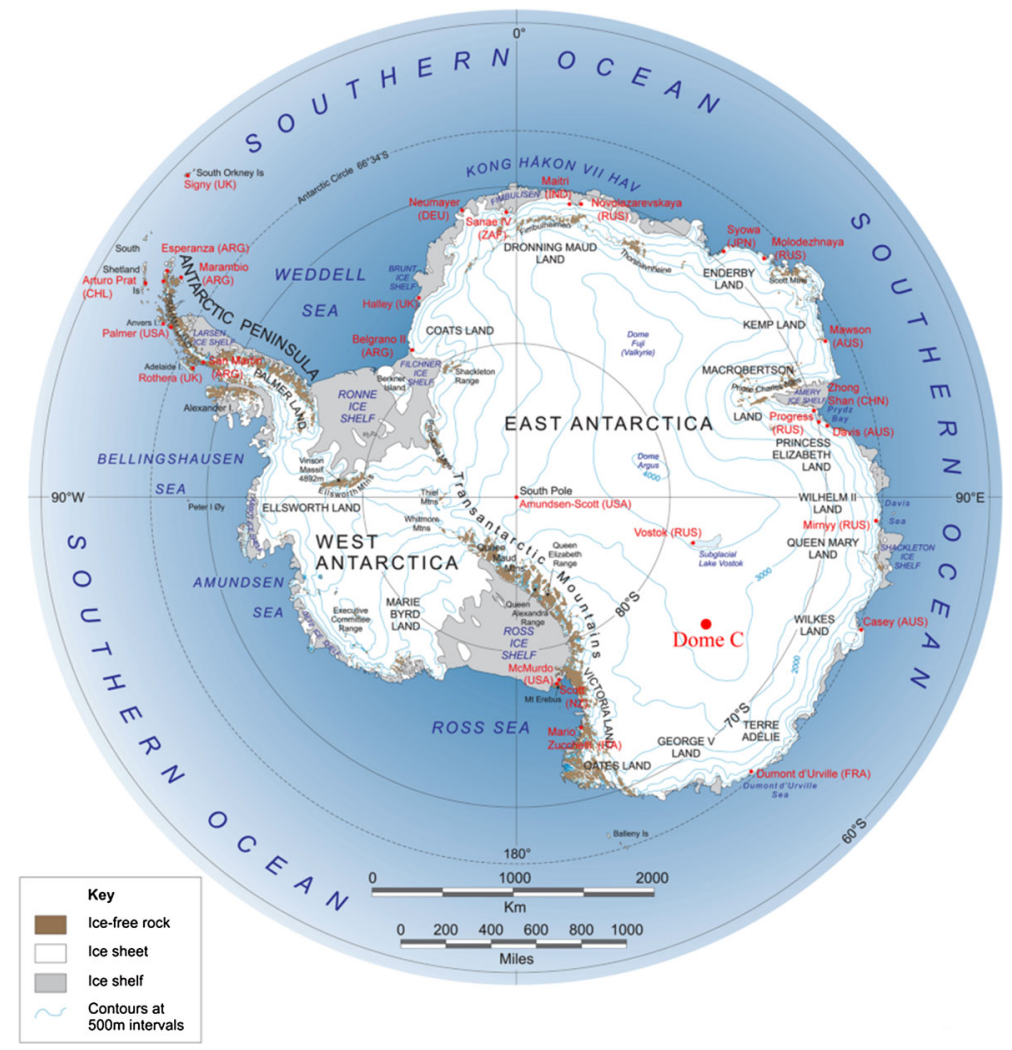

Fig. 2 Geographical map of Antarctica, with the position of Dome C, where the French-Italian station of Concordia is located

\subsection{Sodar Measurements}

An advanced version of a high-resolution sodar (Argentini et al. 2012) developed by the Institute of Atmospheric Sciences and Climate of the National Research Council of Italy (ISAC-CNR) was used for observations of the turbulence structure in the ABL at altitudes from $2 \mathrm{~m}$ up to $200 \mathrm{~m}$ above the surface (with a vertical resolution of $\approx 2 \mathrm{~m}$ ). The sodar has collected data continuously since 20 January 2014, and for this study, we used data collected up to the end of February 2014 . The acoustic pulse with a carrier frequency of $\approx 4800 \mathrm{~Hz}$ had a duration of $10 \mathrm{~ms}$ and was emitted every $2 \mathrm{~s}$. The four vertically-pointed sodar antennae (three transmitting horns and one receiving parabolic dish with a noise-protection shield) (Fig. 3a) were installed $400 \mathrm{~m}$ south-west of the main buildings of the Concordia station. This position was chosen considering the prevailing atmospheric flow to minimize the influence of the station buildings.

Acoustic remote sensing, based on the scattering of acoustic waves by small-scale turbulent temperature and wind fluctuations, provides a clear pattern of the structure of the ABL (Brown and Hall 1978). Sodar allows continuous monitoring of vertical profiles of the temperature structure parameter $C_{T}^{2}$, since the intensity of the backscattered acoustic signal is proportional to $C_{T}^{2}$ (Kallistratova 1962; Tatarskii 1971). The parameter $C_{T}^{2}$ is a proportionality factor in the 2/3-law for the structure function $D_{T}$, valid within the inertial subrange of locally isotropic turbulence (Obukhov 1949), 

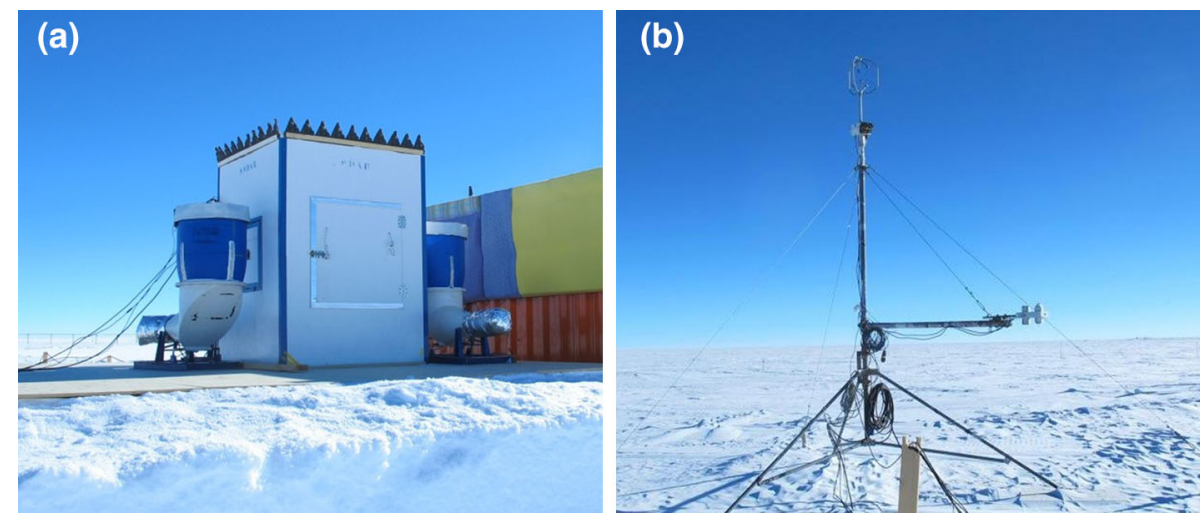

Fig. 3 a Sodar antennae. b The sonic anemometer USA-1 and the net radiometer CNR1

$$
D_{T}(r) \equiv \overline{\left[T^{\prime}\left(\mathbf{r}_{1}\right)-T^{\prime}\left(\mathbf{r}_{2}\right)\right]^{2}}=C_{T}^{2} r^{2 / 3}
$$

where $T^{\prime}(\mathbf{r})$ is the temperature fluctuation around its mean at the point $\mathbf{r}$, and $r=\left|\mathbf{r}_{1}-\mathbf{r}_{2}\right|$ is the distance between points $\mathbf{r}_{1}$ and $\mathbf{r}_{2}$. In acoustic remote sensing, $C_{T}^{2}$ is determined from measurements of the intensity of the backscattered acoustic signal (Tatarskii 1971),

$$
C_{T}^{2}=0.25 \times 10^{3} T^{2} k^{-1 / 3} \sigma_{180}
$$

where $\sigma_{180}$ is the effective backscattering cross-section per unit of scattering volume per unit solid angle, $T$ is the absolute temperature, and $k$ is the wavenumber. In the short form, the relationship between $C_{T}^{2}(z)$ and the measured intensity of the sodar electric return signal $I$ is

$$
C_{T}^{2}(z)=B\left(P_{t}, k, T, c, \tau, S\right) I(z) z^{2} \exp (4 a z),
$$

where $B$ is constant that can be calculated from a complex calibration procedure (Danilov et al. 1994) or determined from comparison with in situ $C_{T}^{2}$ measurements (Petenko et al. $2014 \mathrm{~b}$ ). Here, $P_{t}$ is the transmitted power, $c$ is the velocity of sound, $\tau$ is the pulse duration, $z$ is the distance of the scattering volume from the transmitter, $S$ is the effective area of the sodar antenna, and $a$ is the absorption coefficient of sound.

Note that only those small-scale turbulent temperature inhomogeneities whose vertical dimensions are equal to one half of the wavelength of the interrogating sound wave produce scattering at an angle of $180^{\circ}$ (Tatarskii 1971). For our sodar these dimensions are $30 \mathrm{~mm}$.

The turbulence structure of the atmosphere is depicted by sodar echograms that show a time-height distribution of $C_{T}^{2}$ (e.g. Brown and Hall 1978), and the possibility of reliable quantitative measurements of $C_{T}^{2}$ by using a sodar was shown in many studies (e.g. Coulter and Wesely 1980; Weill et al. 1980; Gur'yanov et al. 1987; Asimakopoulos et al. 1983; Danilov et al. 1994). The applicability of the concept of locally isotropic turbulence, and consequently the structure parameter $C_{T}^{2}$ and Eqs. 1-3, to the turbulent field within wavelike layers will be discussed in Sect. 3, following a detailed description of the observed characteristics of quasi-periodical undulations. 


\subsection{Other Measurements}

Air temperature, wind speed and direction, humidity, pressure measurements were provided by an automatic weather station (AWS) Milos 520 (Vaisala) that was located $500 \mathrm{~m}$ from the sodar with an acquisition rate of 1 point $\min ^{-1}$ at heights of 1.4 and $3.6 \mathrm{~m}$ above the surface for temperature and wind, respectively. A net radiometer type CNR1 (Kipp \& Zonen) was used for radiation measurements, and an ultrasonic anemometer USA-1 (Metek) was used for measurements of parameters characterizing small-scale turbulence. A mast equipped with the net radiometer at a height of $1.2 \mathrm{~m}$ and the sonic at a height of $3.5 \mathrm{~m}$ (Fig. 3b) was installed about $15 \mathrm{~m}$ from the sodar antennae. All data were quality controlled, and to remove outliers from the observations, a median absolute deviation filter (Barnett and Lewis 1984; Petenko et al. 2014a) was applied to the measured time series.

To determine $C_{T}^{2}$ from air temperature and wind velocity sonic data (Kohsiek 1982), the line between $\mathbf{r}_{1}$ and $\mathbf{r}_{2}$ in Eq. 1 is chosen in the direction of the mean horizontal flow. With the assumption of validity of Taylor's frozen turbulence hypothesis, $r=V \delta t$, where $V$ is the mean wind speed, $\delta t$ is the timestep between samples. Sonic data were used to calibrate the sodar measurements and to convert the sodar return signal intensity $I(z)$ to values of $C_{T}^{2}(z)$. The calibration procedure was the same as described in Petenko et al. (2014b): based on the validity of the Obukhov-Wyngaard " $z^{-4 / 3}$ " height dependence of $C_{T}^{2}$ for convective conditions, we calculated the corresponding values for each range gate of the sodar profile from the sonic $C_{T}^{2}$ measured at $3.5 \mathrm{~m}$. The converting coefficients $C=$ $C_{T}^{2}(z) /\left(I z^{2} \exp (4 a z)\right)$ at several levels were then averaged providing the value $C=(2.67 \pm$ $0.58) \times 10^{-9} \mathrm{~K} \mathrm{~m}^{-2 / 3} \Delta^{-2}$ to give $C_{T}^{2}$ values expressed in units of $\mathrm{K} \mathrm{m}^{-2 / 3}$, where $\Delta$ is the analog-to-digital converter count. In addition, temperature and wind-velocity profiles from a 45-m tower located at a distance of approximately $1 \mathrm{~km}$ were available; see a description of the tower equipment in Genthon et al. (2013).

\subsection{Meteorological Conditions}

The histograms shown in Figs. 4 and 5 give an indication of the statistical distributions of the relevant meteorological variables measured by the AWS and the radiometers near the surface. The temperature varies in the range -60 to $-25^{\circ} \mathrm{C}$ (Fig. 4a), with the average daily temperature variation (the difference between maximum and minimum values) of about $15^{\circ} \mathrm{C}$. The wind regime (observed at $3.6 \mathrm{~m}$ ) was characterized mainly by low $\left(<4 \mathrm{~m} \mathrm{~s}^{-1}\right)$ and moderate (4-6 $\mathrm{m} \mathrm{s}^{-1}$ ) wind speeds and wind directions from the south and south-west sectors as shown by the frequency distribution wind rose in Fig. $4 \mathrm{~b}$. Low wind speeds were observed $>80 \%$ of the time, moderate wind speeds were observed for $\approx 15 \%$ of the time, with wind speeds $>7 \mathrm{~m} \mathrm{~s}^{-1}$ usually occurring during synoptic perturbations due to intrusions of maritime airmasses from coastal zones accompanied by cloudiness and strong turbulence extending up to a few hundred metres. The values of the downwelling longwave radiative flux $L W \downarrow$ (Fig. 5a) and shortwave radiation $S W \downarrow$ (Fig. 5b) were used as an objective criterion for the presence of clouds or mist.

\section{Results}

\subsection{Diurnal Behaviour of the Meteorological and Turbulent Parameters}

First, we consider the diurnal variations of the relevant mean and turbulent parameters measured by the sonic thermo-anemometer at a height of $3.5 \mathrm{~m}$. Parameters relevant to the 

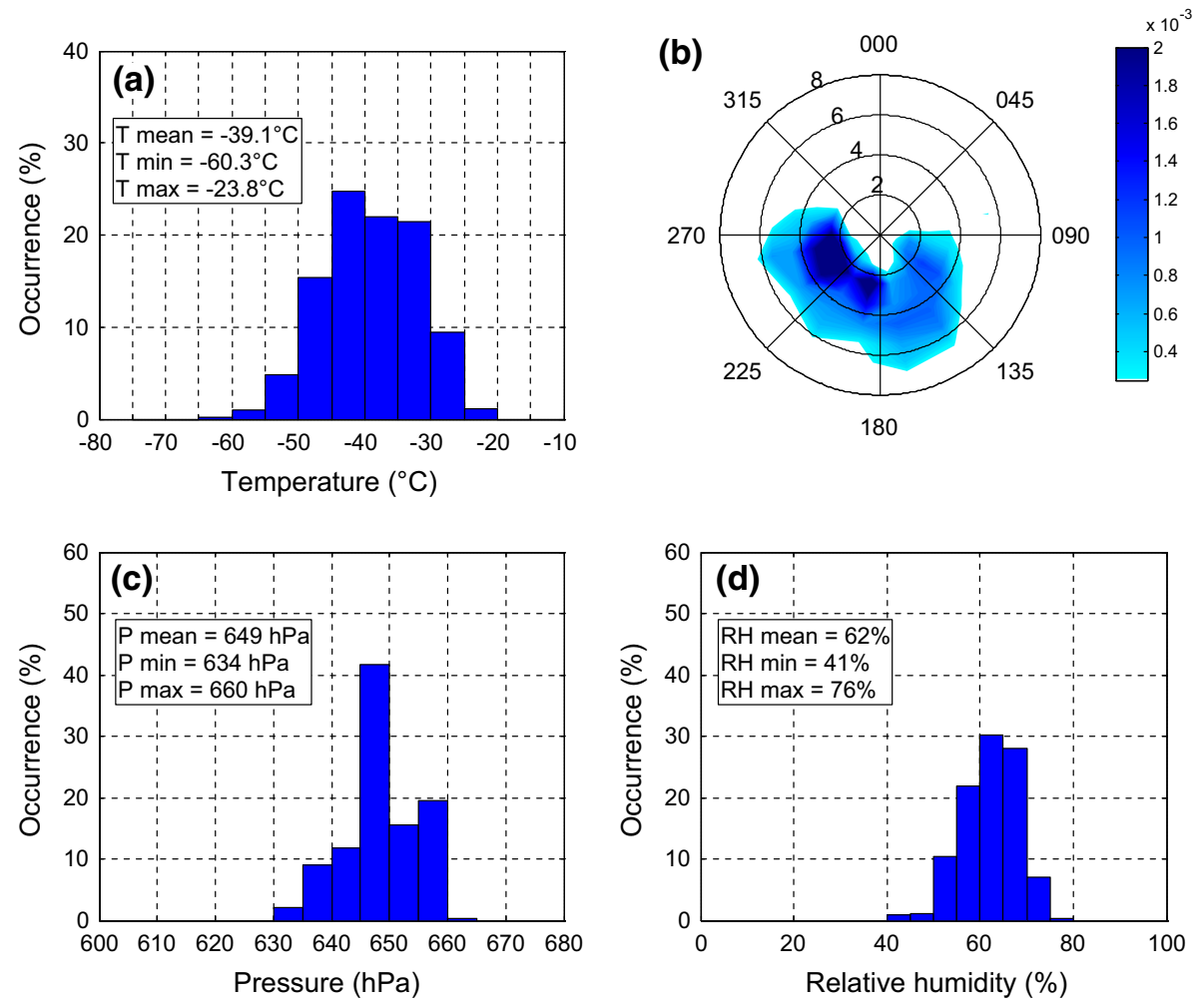

Fig. 4 Statistics of the meteorological variables for selected days with fair weather conditions in the period 20 January to 25 February 2014. Histograms of: a temperature, c pressure, d relative humidity. b wind rose diagram showing the joint probability distribution of wind speed and wind direction (colour intensity is proportional to the value of the joint probability density function)
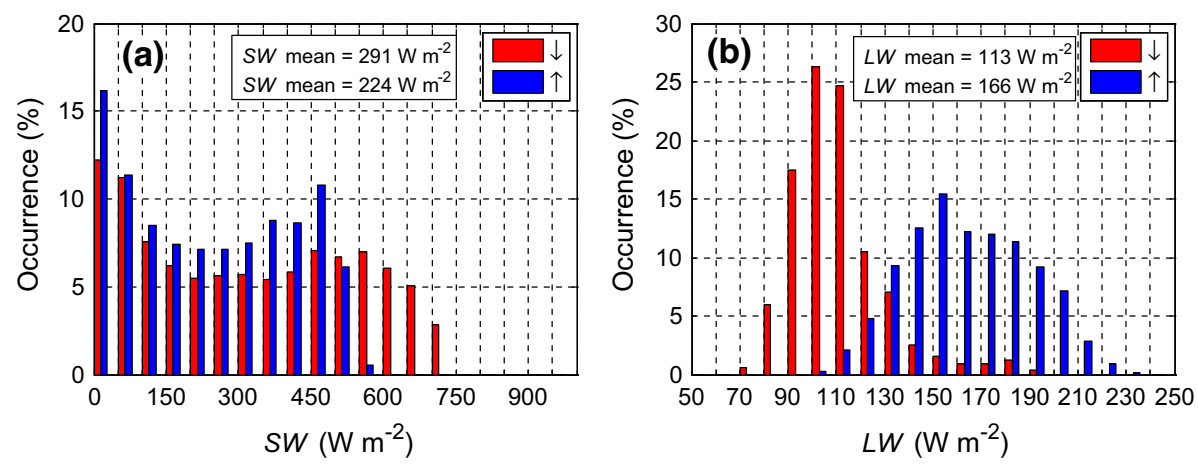

Fig. 5 Histograms of downward (red) and upward (blue) radiation components for selected days with fair weather conditions in the period 20 January to 25 February 2014: a shortwave, b longwave

study of thermal and mechanical turbulence are considered: (1) temperature $T$ (Fig. 6a), sensible heat flux $H_{0}$ (Fig. 6c), and temperature structure parameter $C_{T}^{2}$ (Fig. 6e); (2) wind speed $V$ (Fig. 6b), friction velocity $u_{*}$ (Fig. 6d), and turbulent kinetic energy $T K E$ (Fig. 6f). 
Concordia-DomeC, 01-02/2014
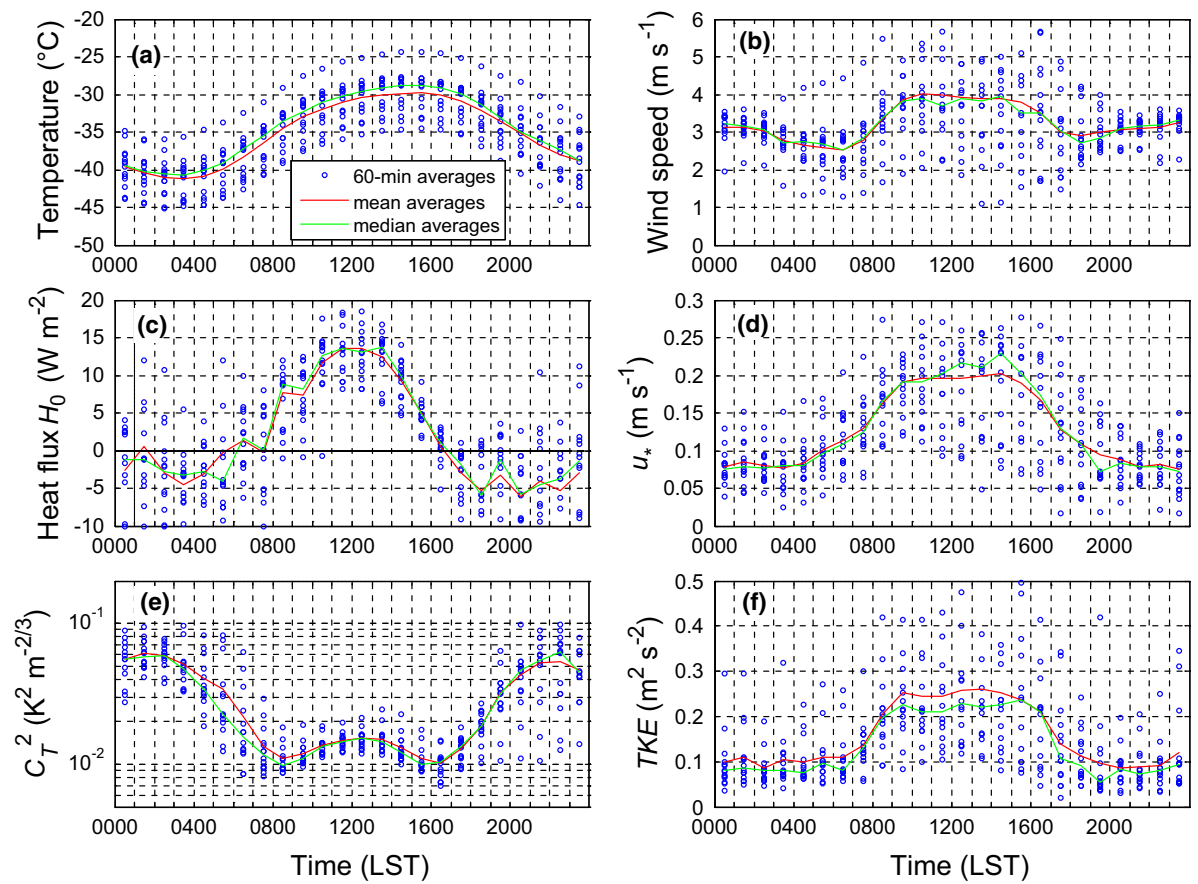

Fig. 6 Diurnal behaviour of selected parameters obtained using a sonic thermometer-anemometer at a height of 3.5 m over 15 selected days in the months of January and February 2014. a temperature, b wind speed, c sensible heat flux $H_{0}$, d friction velocity $u_{*}$, e temperature structure parameter $C_{T}^{2}$, f turbulent kinetic energy $T K E$. Circles are the 60-min averaged values for individual days. Solid lines show the values averaged over the all days; red and green lines show arithmetic and median averages, respectively

Definitions of these turbulent parameters can be found in Tatarskii (1971). All plots show the 60-min average measurements presenting the available dataset for 15 days with fair weather conditions. Almost all of these parameters show a typical diurnal behaviour that is consistent with the turbulent ABL structure shown by the sodar (Fig. 7a) and does not differ from the results of previous studies at Dome $\mathrm{C}$.

The "daytime" behaviour of $C_{T}^{2}$ near the surface shows a remarkable repeatability with relative variations of 13-25\%, with two local minima around 0800 and 1600 LST (local standard time $=\mathrm{UTC}+8)$ similar to that observed at mid latitudes (e.g., Beyrich et al. 2005; Wood et al. 2013). The diurnal maximum observed around 1300 LST is markedly lower than nocturnal $C_{T}^{2}$ values. The other turbulence parameters indicate a much larger variability: for $u_{*}-27-42 \%, H_{0}-28-51 \%, T K E-44-56 \%$. We emphasize that the data presented are for fair weather conditions.

\subsection{4-h Behaviour of the ABL Spatial and Temporal Structure}

Here we consider the diurnal behaviour of the spatial and temporal distribution of turbulence together with variations of selected atmospheric parameters. As a representative example, we chose the observations made on 3 February 2014. The sodar echogram in Fig. 7a shows the 24-h behaviour of a time-height cross-section of the turbulence intensity in the ABL during 

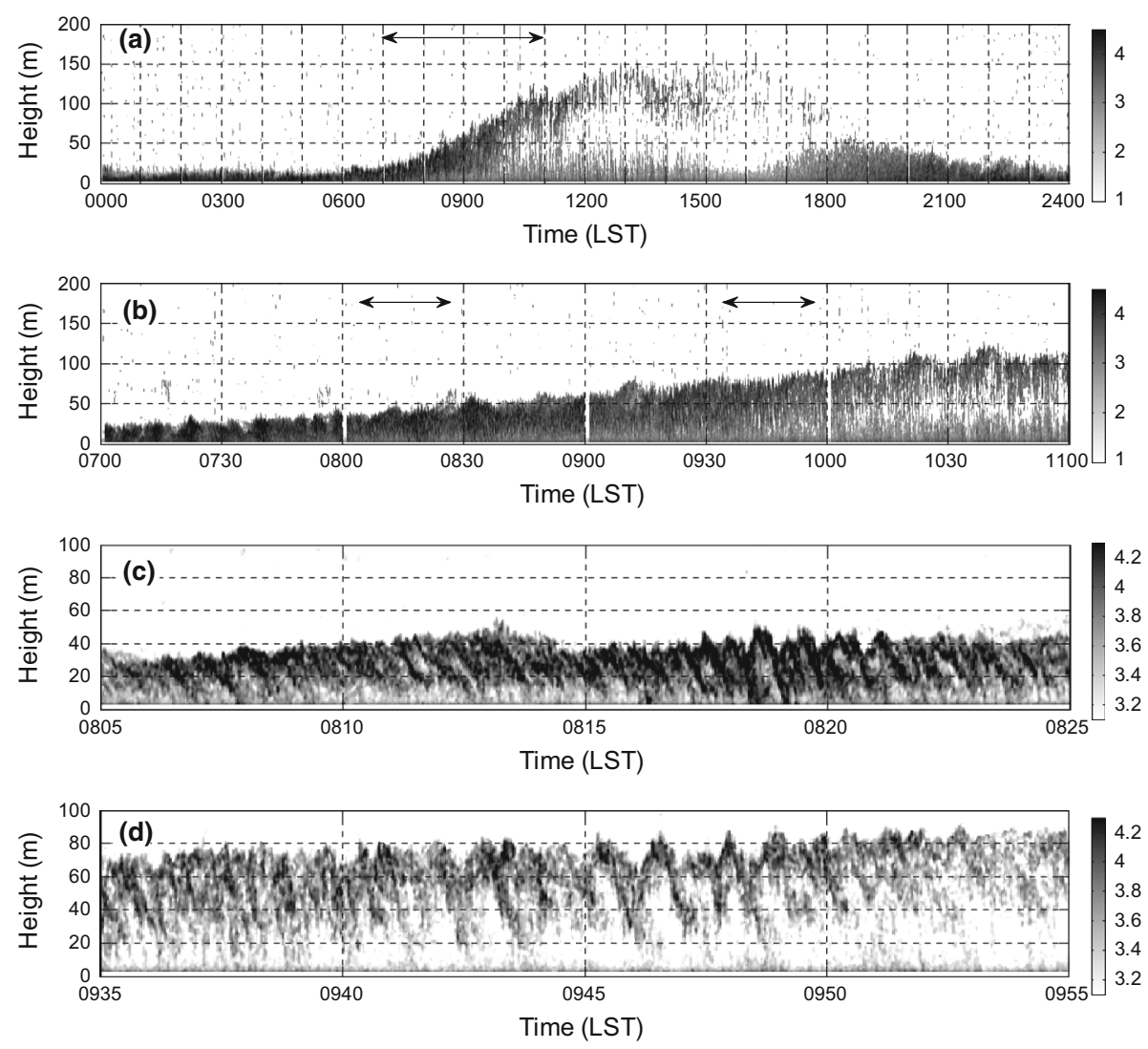

Fig. 7 a Typical sodar echogram showing the diurnal variation of the ABL structure in summer (3 February 2014). The grey-scale intensity is proportional to the thermal turbulence intensity. Double arrows show the time location of the selected close-ups. b 4-h close-up of the echogram for the same day (0700-1100 LST). c, d Two 20-min close-ups of the echogram with undulation pattern during morning development of the convective ABL

this day. During the "nighttime", the turbulent ABL is shallow with height $<10 \mathrm{~m}$, with $C_{T}^{2}$ values within it reaching $5 \times 10^{-2} \mathrm{~K}^{2} \mathrm{~m}^{-2 / 3}$. After $0700 \mathrm{LST}$, the turbulent layer deepens reaching heights of 150-200 $\mathrm{m}$ and capping the convective boundary layer growing from the surface. After 1600 LST, the elevated turbulent layer disappears. After 2100 LST, the surface-based turbulent layer returns to a shallow depth and the thermal turbulence within it intensifies having values of $C_{T}^{2}$ higher than those during the "daytime". A more detailed analysis of the echograms shown in Fig. 7 is made in Sect. 3.2.

Temperature, wind speed, shortwave and longwave downward radiation components can be assumed as relevant variables characterizing the state of the ABL (Argentini et al. 2014; Pietroni et al. 2012, 2014). The time series of these parameters for 3 February 2014 are shown in Fig. 8. The 24-h variation of temperature and wind speed on 3 February 2014 shown in Fig. $8 \mathrm{a}, \mathrm{b}$ are rather close to the mean diurnal behaviour of these parameters given in Fig. 6a, $\mathrm{b}$, confirming that this example is quite representative.

In Fig. 9, the 24-h behaviour of the vertical structure of temperature and wind speed measured at six levels of the 45-m meteorological tower on 3 February 2014 is shown. 

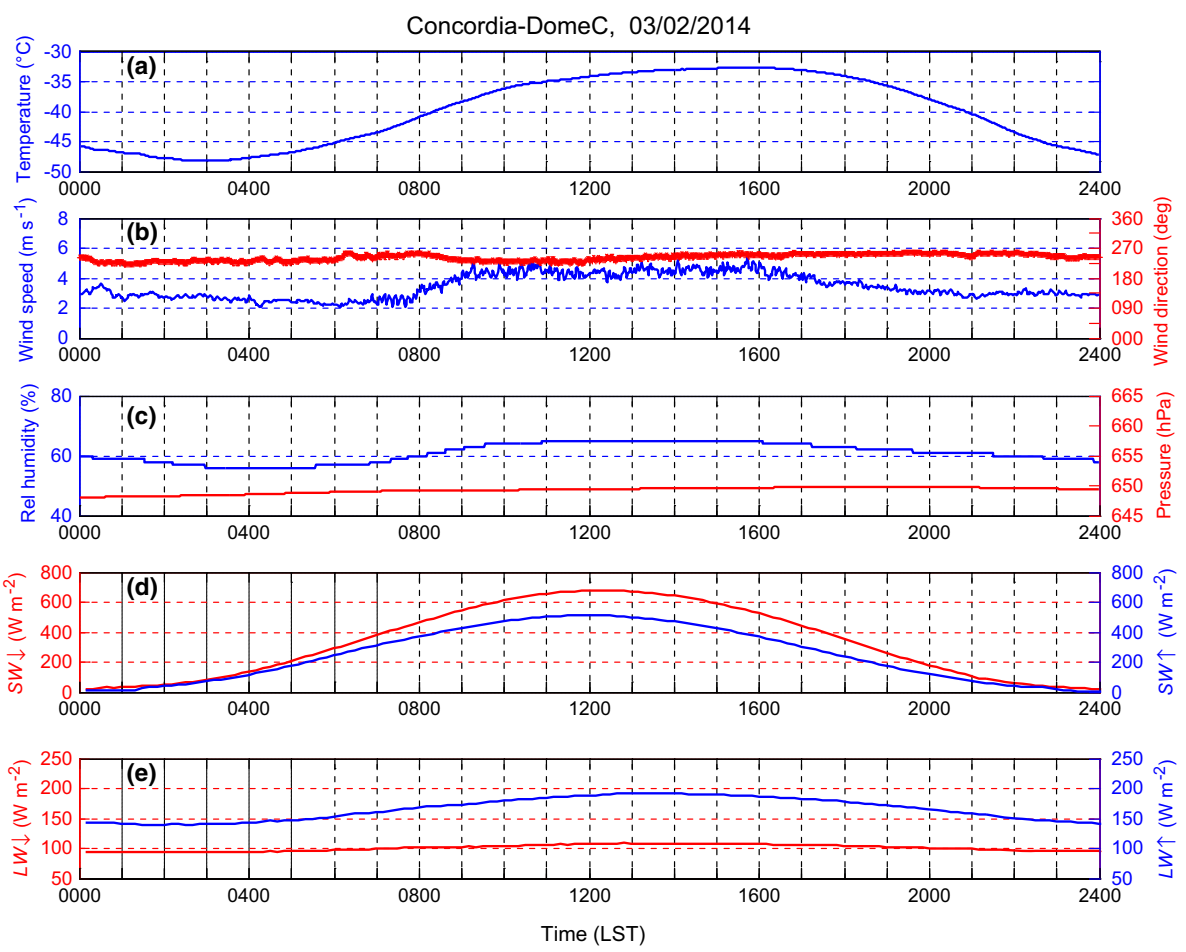

Fig. 8 24-h behaviour of a temperature at a height of $1.4 \mathrm{~m}, \mathbf{b}$ wind speed and direction at a height of $3.6 \mathrm{~m}$, $\mathbf{c}$ relative humidity and pressure, $\mathbf{d}$ shortwave radiation components, and e longwave radiation components on 3 February 2014

The temperature field shows clear alternation between the strong surface-based inversion at nighttime and the weak convective layer capped with an elevated inversion during the daytime. The wind field is characterized by strong wind shear at night that disappears at noon.

Figure 10 shows the time series of $C_{T}^{2}$ measured by the sonic at $3.5 \mathrm{~m}$ and by the sodar at 7 and $14 \mathrm{~m}$. Both the sonic-measured $C_{T}^{2}$ (Fig. 6e) and that derived from the sodar return power (Fig. 10) show that the "nocturnal" values within the surface-based turbulent layer are in many cases larger the "diurnal" ones. This means that small-scale temperature fluctuations under stable stratification are significant and can be much larger than those observed in convection. This behaviour was not observed in previous experiments, due to the lack of reliable sodar measurements below $30 \mathrm{~m}$ at this site. Although $C_{T}^{2}$ itself is not considered in any ABL model, this characteristic, and especially its variation with height, could be used to estimate more conventional parameters such as the turbulent fluxes or the mixing-layer height. Such attempts were made by Coulter and Wesely (1980), Coulter (1990), Wood et al. (2013).

\subsection{Wavy Structures During the Morning Evolution of the ABL}

Fifteen days with fair weather conditions (from 20 January to 25 February 2014) were selected for analysis. The diurnal evolution of the turbulence structure in the ABL on these days was similar to that presented in Fig. 7a. We focus on the specific transition period in the morning 

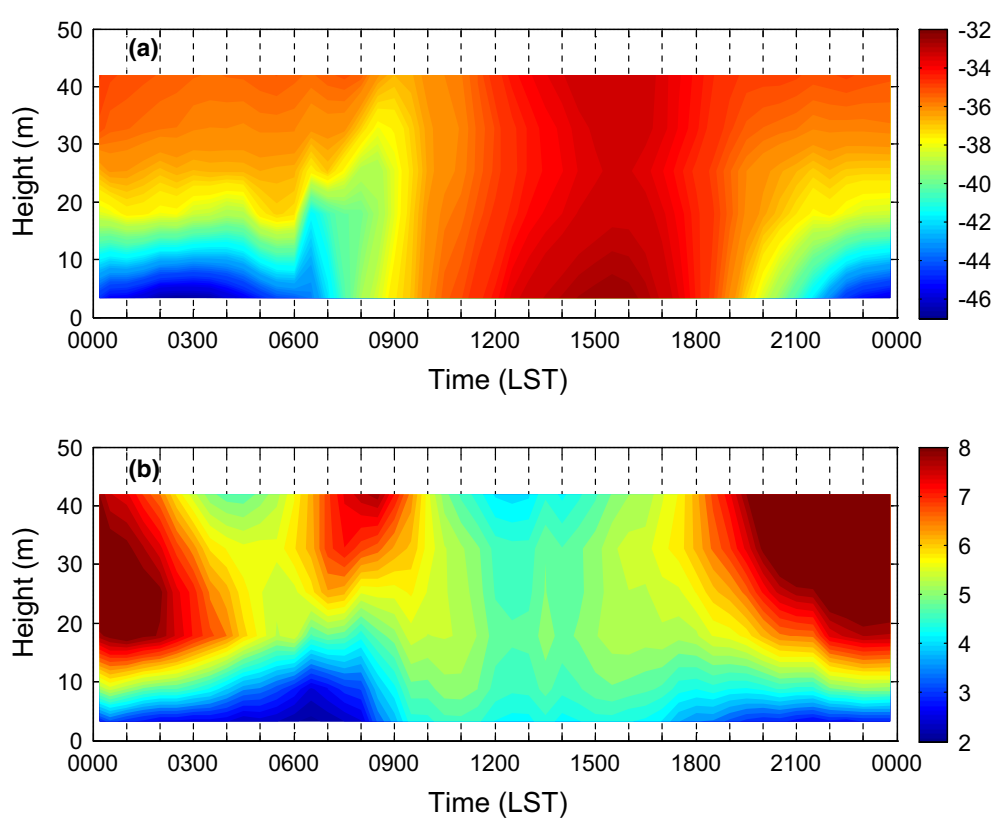

Fig. 9 24-h behaviour of the vertical structure of a temperature and $\mathbf{b}$ wind speed measured at the 45-m tower on 3 February 2014

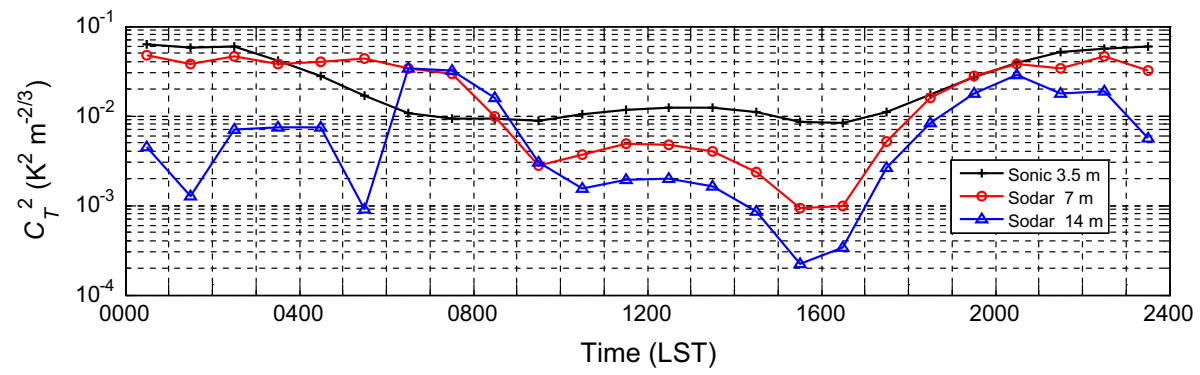

Fig. 10 24-h behaviour of $C_{T}^{2}$ observed by the sonic at a height of $3.5 \mathrm{~m}$ (black) and by the sodar at two heights $7 \mathrm{~m}$ (red) and $14 \mathrm{~m}$ (blue) on 3 February 2014

hours, when convection begins to develop and the turbulent layer (normally associated with a layer of temperature inversion) begins to rise and ascend, capping the layer of convection. The evolution of the profiles of temperature and wind speed in this period are shown in Fig. 11, where the rising inversion layer and the substantial wind shear are seen. Sodar echograms always showed the presence of undulations within an elevated turbulent layer. We refer to the "wavy layer" when we consider the whole layer of wave activity visible on the echograms in Fig. 7 and extending for heights of several tens of metres. The wavy layer elevates as a whole and contains a wavelike pattern, or braids that have a noticeable turbulent contour as in Fig. 7c, d. As shown by the echograms in Fig. 7c, d, the braid-type quasiperiodic structures occupy (and, in fact, form) the whole turbulence layer. They behave as waves induced by the $\mathrm{KH}$ instability within an elevated inversion layer. A schematic diagram of characteristics of the wavelike pattern in the braid region (its vertical dimensions 

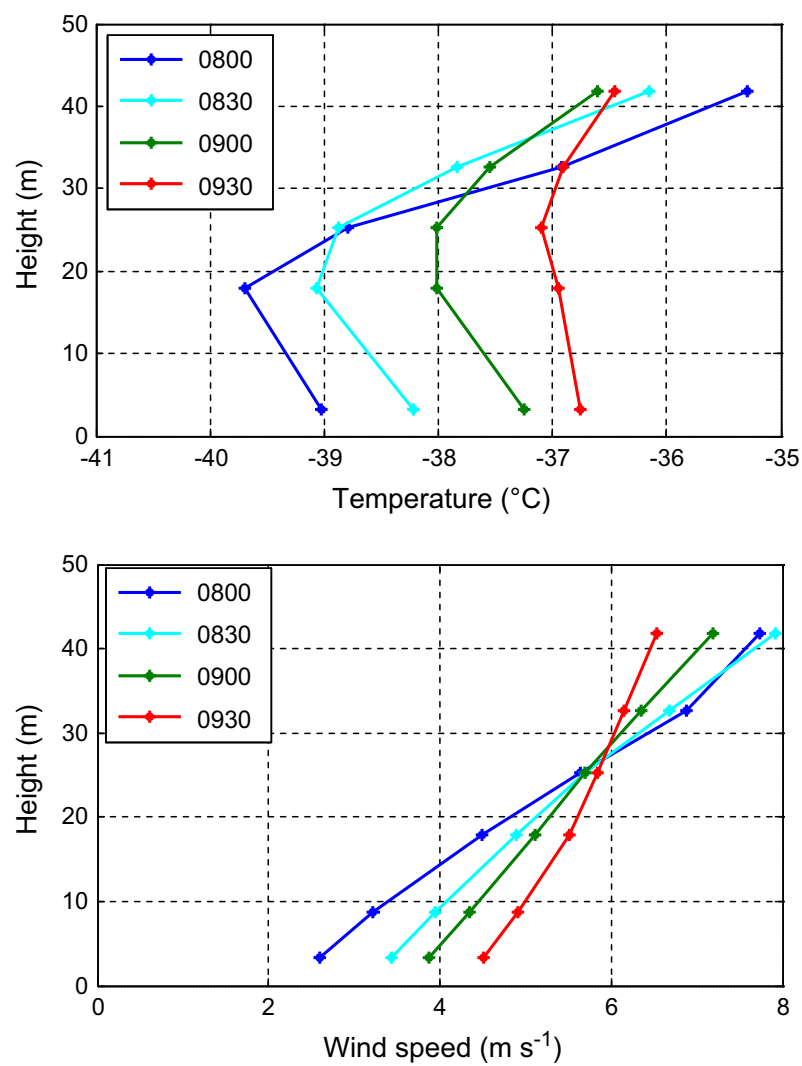

Fig. 11 Profiles of temperature (top panel) and wind speed (bottom panel) averaged over 30 min for 3 February 2014, 0800-1000 LST

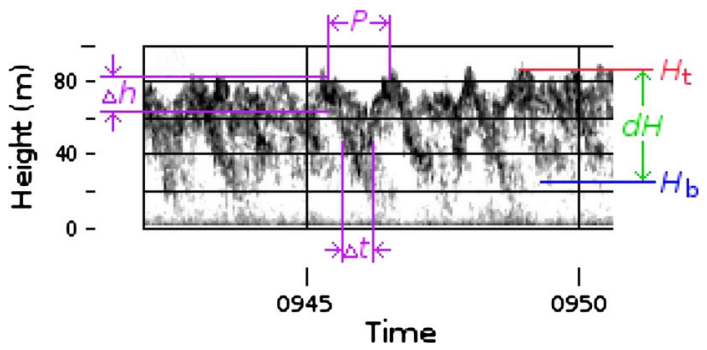

Fig. 12 Schematic diagram of characteristics of the wavelike pattern with indication of the symbols used in Fig. 13 and in Table 1. $P$ quasi-period of the wave, $H_{t}$ height of the top of the wavy layer, $H_{b}$ height of the bottom of the wavy layer, $\mathrm{d} H$ vertical extension of the whole layer of wave activity, $\Delta h$ the vertical thickness of the high $C_{T}^{2}$ layer measured at the wave crests, $\Delta t$ time duration of the turbulent contour of the wavelike pattern

and time durations) is shown in Fig. 12. Periods of these structures range mainly between 40 and $50 \mathrm{~s}$.

The vertical dimension of these turbulent contours increases during the morning hours as the entire elevated turbulent layer rises and spreads As an estimate of the vertical extension of the whole wavy layer we take the difference $\mathrm{d} H=H_{t}-H_{b}$ between two characteristic 


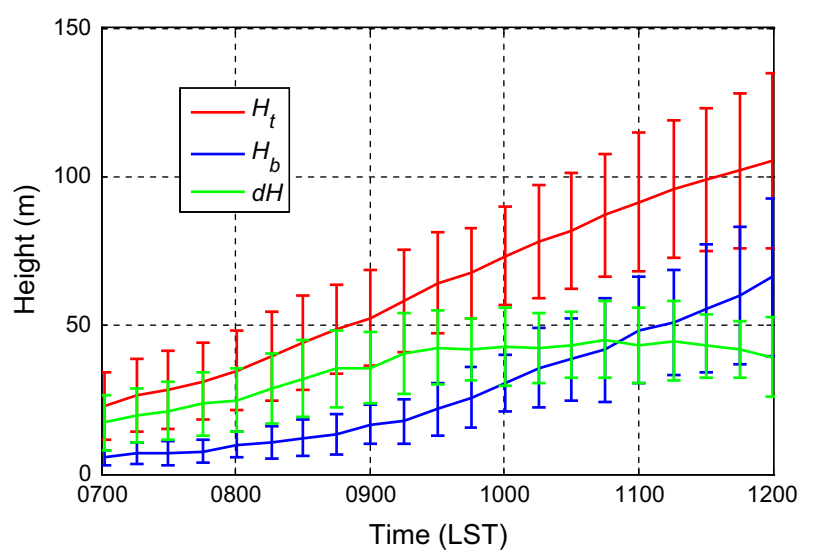

Fig. 13 Time behaviour of $H_{t}$ (red), $H_{b}$ (blue) and $\mathrm{d} H$ (green) for the morning period 0700-1200 LST averaged over selected fifteen days with fair weather. Vertical bars show the standard deviation of the presented characteristics

heights: (1) the height $H_{t}$ of the upper boundary of the braid contour at the crests of the wavy layer (see Fig. 12), and (2) the height $H_{b}$ of the lowest boundary of the braid contour at the hollows. In Fig. 13, the time behaviour of $H_{t}, H_{b}$, and $\mathrm{d} H$ is shown for the period of the morning evolution 0700-1200 LST averaged over 15 days with fair weather conditions. While the top and bottom heights continue to grow, the thickness $\mathrm{d} H$ of the layer seems to reach an equilibrium value of $45 \pm 10 \mathrm{~m}$ after $0930 \mathrm{LST}$.

Note that spatial dimensions of the braid contours are not small. Rough visual estimates of the vertical thickness of the contours at the wave crests, $\Delta h$, in Fig. 7c, $\mathrm{d}$ are about 15-20 $\mathrm{m}$. The horizontal thickness $\Delta x=V \Delta t$ estimated using Taylor's hypothesis is about $50-100$ $\mathrm{m}$. These values that might be considered as the outer scale of turbulence $L_{0}$ provide a sufficiently large inertial range of turbulence within the contours. Note that the scale of turbulent inhomogeneities which provides backscattering is equal to one half of an interrogating sound wavelength, which for the sodar used here is about $0.03 \mathrm{~m}$. Such a scale, apparently, lays within the inertial range. Thus, we have sufficient reasons to apply Eq. 1-3 to the case of the wave activity.

A spectral analysis of sodar $C_{T}^{2}$ time series was used to accurately estimate the periods of the wavy structures shown in Fig. 7c, d. Before the spectral processing, some filtering procedures were applied to reduce the noise impact and to extract the regular part of the undulation processes. A bi-dimensional median filter, median absolute deviation filter and a low-pass filter were used. The power spectra were calculated using Welch's averaged modified periodogram method of spectral estimation (see Welch 1967). All the spectra were then normalized by the variances of the time series. Spectra of $C_{T}^{2}$ at three heights are shown as a function of period in Fig. 14 separately for both the considered close-ups. The heights were chosen to be within the layer with wavy structures: 19, 24 and $32 \mathrm{~m}$ for the first close-up, and 43,49 , and $54 \mathrm{~m}$ for the second one. The spectra show peaks at the similar periods to those estimated earlier visually from the echograms and time series. In both the cases, the spectra for the selected heights are quite similar, and the peak positions are close to each other. In the first close-up, the main peaks are located at periods of about 42-43 s; in the second close-up, the positions of the peaks are shifted to $\approx 50 \mathrm{~s}$. These periods are less than the buoyancy periods corresponding to the Brunt-Väisälä frequency, which are estimated to 

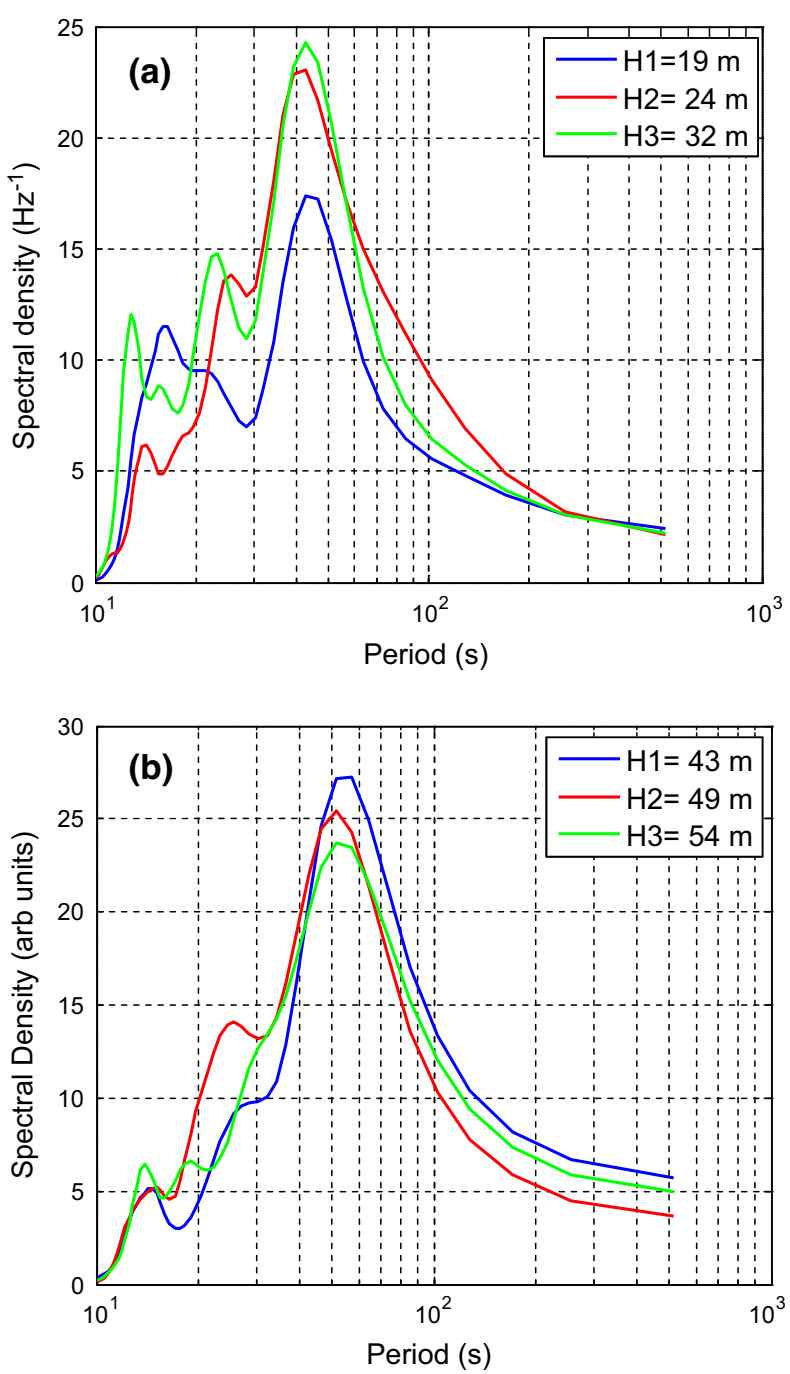

Fig. 14 Power spectra of $C_{T}^{2}$ at three heights for 20-min time series measured on 3 February 2014 a $0805-$ 0825 LST and b 0935-0955 LST. All spectra are normalized by the variance of the respective time series and are presented as a function of period

be about 75 and $150 \mathrm{~s}$ for the considered time intervals. The histogram in Fig. 15 shows the distribution of periods observed in all cases of wave activity.

The horizontal scale that can be roughly attributed to the wavelength has been calculated as $\lambda=V P$ assuming the validity of Taylor's frozen hypothesis, where $P$ is the wave period, and $V$ is the wind speed. For $P \approx 40-50 \mathrm{~s}$ and $V$ taken from the 45-m tower we estimate $\lambda$ as approximately $250-350 \mathrm{~m}$. Of course, Taylor's hypothesis is applicable to small-scale turbulence only, not to waves. In fact, we apply it not to waves, but to the small-scale turbulent fluctuations, which are modulated by standing (relative to the mean flow) KH billows. The assumption that the $\mathrm{KH}$ billows are stationary is based also on the experimental results by Gossard et al. (1970) showing that the phase speed of KH waves is close to the velocity of 


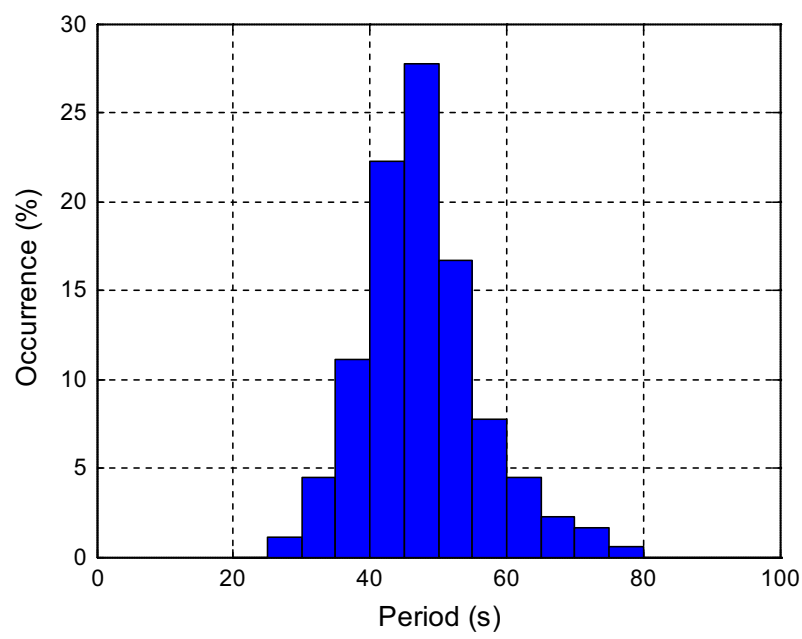

Fig. 15 Histogram of wave periods for all observation times

Table 1 Averaged characteristics of the wave processes during the morning development of the convective ABL for the period 21 January-25 February 2014

\begin{tabular}{|c|c|c|}
\hline Characteristic & Method of determination & \\
\hline $\begin{array}{l}\text { 1. Period } P \text { (time distance between two } \\
\text { consecutive crests of wave contour) }\end{array}$ & $\begin{array}{l}\text { (1) Visually from sodar echograms or } C_{T}^{2} \\
\text { time series at different heights } \\
\text { (2) using spectral analysis }\end{array}$ & $40-50 \mathrm{~s}$ \\
\hline 2. Wavelength $\lambda=V P$, & Taylor's hypothesis & $250-350 \mathrm{~m}$ \\
\hline $\begin{array}{l}\text { 3. Horizontal thickness of the turbulent } \\
\text { contour of wavy pattern } \Delta x=V \Delta t\end{array}$ & $\begin{array}{l}\text { Visually from sodar echograms or } C_{T}^{2} \text { time } \\
\text { series at different heights using } \\
\text { Taylor's hypothesis }\end{array}$ & $50-100 \mathrm{~m}$ \\
\hline $\begin{array}{l}\text { 4. Vertical thickness of the of the turbulent } \\
\text { contour of wavy pattern } \Delta h\end{array}$ & $\begin{array}{l}\text { Visually from sodar echograms or instant } \\
C_{T}^{2} \text { profiles }\end{array}$ & $15-20 \mathrm{~m}$ \\
\hline $\begin{array}{l}\text { 5. Vertical extension of the whole layer of } \\
\text { wave activity } \mathrm{d} H\end{array}$ & Visually from sodar echograms & $20-60 \mathrm{~m}$ \\
\hline
\end{tabular}

the ambient wind at the height of maximum shear. We are aware that this approach is quite crude, but in this experiment we cannot suggest any more elaborate and reasonable way to estimate a horizontal scale of the wavy structures from single-point measurements. This is a tentative step to obtain information on the spatial characteristics of the wavy pattern.

Two other spatial characteristics which can be determined from the available data are the thicknesses of the contour at the wave crests in the horizontal and vertical directions. A rough estimate can be made by looking at the sodar echograms. The vertical thickness of an inclined fine layers is estimated as 10-15 m; the vertical thickness of the contours at the wave crests is estimated as $15-20 \mathrm{~m}$. Table 1 summarizes the values obtained for geometric parameters of the wave pattern.

Several theoretical works (e.g., Drazin 1958; Davis and Peltier 1976) provide estimates of the relation $\lambda=A \mathrm{~d} H$ between the wavelength $\lambda$ and the thickness of the layer $\mathrm{d} H$ for waves that are due to shear-flow instability in the gravity field. The numerical coefficient 
$A$ varies in different theoretical works between 4 and 7.6, being dependent on the assumed model of vertical variation of velocity and density, as well as of the Richardson number. In some experimental studies (e.g., Scorer 1969; Eymard and Weill 1979; Lyulyukin et al. 2015), values of $A$ from 3 to 20 were obtained. From the measurements of Table 1, the ratio $\lambda / \mathrm{d} H$ is roughly estimated to be between 5 and 12 . As the experimental estimate is close to the theoretical one, we believe that the observed wavy structures are produced by $\mathrm{KH}$ disturbances.

\section{Summary}

We used measurements from a field experiment held during the summer months (JanuaryFebruary) of 2014 at the French-Italian station of Concordia at Dome C in Antarctica to investigate processes occurring in the polar ABL. A distinct and representative diurnal cycle of the ABL turbulence structure and of the relevant meteorological and micrometeorological characteristics was documented using remote-sensing and in situ measurements. The diurnal behaviour shows the alternation of a surface-based temperature inversion and convection capped by the inversion layer. The results are consistent with those from previous studies (e.g., Argentini et al. 2005; Pietroni et al. 2012). The "nighttime" (from 1800 to 0700 LST) $C_{T}^{2}$ values near the surface are markedly higher than those observed during the "daytime" (from 0800 to $1800 \mathrm{LST}$ ). The "daytime" behaviour of $C_{T}^{2}$ is characterized by a remarkable periodicity having a small variation in comparison with other turbulence parameters.

We mainly focused on the behaviour of the ABL during the development of convection under the capping inversion layer during the morning hours. The use of an advanced highresolution sodar provided evidence of new features in the spatial and temporal structure of turbulence, which shows clearly the presence of wavelike processes accompanying the development of convection. Within the elevated inversion layer that ascends when convection develops near the surface, high-resolution sodar echograms present regular fine-scale layers with a braid pattern that resembles waves due to the $\mathrm{KH}$ instability. Earlier, similar wavelike patterns were observed in Antarctica (Neff et al. 2008; Petenko et al. 2013; Argentini et al. 2014; Kouznetsov and Lyulyukin 2014), but were not associated with the morning development of convection.

The periods of the observed wavy structures range mainly between 40 and $50 \mathrm{~s}$, while rough estimates of the horizontal scales made using Taylor's hypothesis provides wavelengths $\lambda$ of $\approx 250-350 \mathrm{~m}$. The horizontal width of individual wavy fine-scale layers ranges between 20 and $60 \mathrm{~m}$, and their vertical thickness at the wave crests is $15-20 \mathrm{~m}$. The depth $\mathrm{d} H$ of the ascending turbulent layer containing waves varies from 20 to $60 \mathrm{~m}$, with $\lambda / \mathrm{d} H$ between 5 and 12 (close to theoretical expectations for $\mathrm{KH}$ waves).

The results call for the development of advanced theoretical approaches that would enable the interaction of convective and wave processes occurring simultaneously to be taken into account.

Acknowledgments This research was supported by the Italian National Research Programme (PNRA), the French Polar Institute (IPEV) as part of French-Italian projects for Dome C and a project COMPASS, and the Russian Foundation for Basic Research (project 16-05-01072). Analysis and data processing were supported by the Russian Science Foundation (project No. 14-27-00134). Our special thanks to G. Mastrantonio for his contribution to the development of sodar equipment and C. Genthon for providing the data from 45-m tower. The authors thank A. Conidi, S. Ciampichetti, and N. Ferrara for the technical support provided in the realization of the sodar antennae and the logistics staff of the Concordia station (F. Valcauda, M. Sanvido, A. Verpillot, C. Montanari, E. D'Eramo, A. Domesi) for its active help during the field work. The authors also thank S. Zilitinkevich, S. Danilov and R. Kouznetsov for useful comments and suggestions. 
Open Access This article is distributed under the terms of the Creative Commons Attribution 4.0 International License (http://creativecommons.org/licenses/by/4.0/), which permits unrestricted use, distribution, and reproduction in any medium, provided you give appropriate credit to the original author(s) and the source, provide a link to the Creative Commons license, and indicate if changes were made.

\section{References}

Argentini S, Petenko I, Mastrantonio G, Bezverkhnii V, Viola A (2001) Spectral characteristics of East Antarctica meteorological parameters during 1994. J Geophys Res 106:12463-12476

Argentini S, Viola A, Sempreviva A, Petenko I (2005) Summer boundary-layer height at the plateau site of Dome C, Antarctica. Boundary-Layer Meteorol 115:409-422. doi:10.1007/s10546-004-5643-6

Argentini S, Mastrantonio G, Petenko I, Pietroni I, Viola A (2012) Use of a high resolution sodar to study surface-layer turbulence at night. Boundary-Layer Meteorol 143:177-188. doi:10.1007/s10546-0119638-9

Argentini S, Petenko I, Pietroni I, Viola A, Mastrantonio G, Casasanta G, Aristidi E, Genthon C (2014) The surface layer observed by a high resolution sodar at Dome C, Antarctica. Annal Geophys 56(5): doi:10. 4401/ag-6347

Asimakopoulos DN, Mousley TJ, Helmis CJ, Lalas DP, Gaynor JE (1983) Quantitative low-level acoustic sounding and comparison with direct measurements. Boundary-Layer Meteorol 27:1-26

Barnett V, Lewis T (1984) Outliers in statistical data. Wiley, New York, 463 pp

Beyrich F, Kouznetsov RD, Leps JP, Lüdi A, Meijninger WML, Weisensee U (2005) Structure parameters for temperature and humidity from simultaneous eddy-covariance and scintillometer measurements. Meteorol Z 14:641-649. doi:10.1127/0941-2948/2005/0064

Brown EH, Hall FF Jr (1978) Advances in atmospheric acoustics. Rev Geophys 16:47-110

Browning KA (1971) Structure of the atmosphere in the vicinity of large-amplitude Kelvin-Helmholtz billows. QJR Meteorol Soc 97:283-299. doi:10.1002/qj.49709741304

Browning KA, Starr JR, Whyman AJ (1973a) The structure of an inversion above a convective boundary layer as observed using high-power pulsed Doppler radar. Boundary-Layer Meteorol 4:91-111

Browning KA, Bryant GW, Starr JR, Axford DN (1973b) Air motion within Kelvin-Helmholtz billows determined from simultaneous Doppler radar and aircraft measurements. Q J R Meteorol Soc 99:608-618. doi:10.1002/qj.49709942203

Casasanta G, Pietroni I, Petenko I, Argentini S (2014) Observed and modelled mixing layer height at Dome C, Antarctica. Part I: the convective boundary layer. Boundary-Layer Meteorol 151:597-608. doi:10.1007/ s10546-014-9907-5

Cohen AE, Cavallo SM, Coniglio MC, Brooks HE (2015) A review of planetary boundary layer parameterization schemes and their sensitivity in simulating southeastern U.S. cold season severe weather environments. Weath. Forecast 30(3):591-612. doi:10.1175/WAF-D-14-00105.1

Coulter RL, Wesely ML (1980) Estimates of surface heat flux from sodar and laser scintillation measurements in the unstable boundary layer. J Appl Meteorol 19:1209-1222

Coulter RL (1990) A case study of turbulence in the stable nocturnal boundary layer. Boundary-Layer Meteorol 53:75-91

Danilov SD, Gur'yanov AE, Kallistratova MA, Petenko IV, Singal SP, Pahwa DR, Gera BS (1994) Simple method of calibration of conventional sodar antenna system. Int J Remote Sensing 15:307-312

Davis PA, Peltier WR (1976) Resonant parallel shear instability in the stably stratified planetary boundary layer. J Atmos Sci 33:1287-1300. doi:10.1175/1520-0469(1976)033<1287:RPSIIT>2.0.CO;2

Drazin PG (1958) The stability of a shear layer in an unbounded heterogeneous inviscid fluid. J Fluid Mech 4:214-224

Esau I, Zilitinkevich S (2010) On the role of the planetary boundary layer depth in the climate system. Adv Sci Res 4:63-69. doi:10.5194/asr-4-63-2010

Eymard L, Weill A (1979) A study of gravity waves in the planetary boundary layer by acoustic sounding. Boundary-Layer Meteorol 17:231-245

Genthon C, Gall'ee H, Six D, Grigioni P, Pellegrini A (2013) Two years of atmospheric boundary layer observations on a 45-m tower at Dome C on the Antarctic plateau. J Geophys Res Atmos 118:32183232. doi:10.1002/jgrd.50128

Gossard EE, Richter JH, Atlas D (1970) Internal waves in the atmosphere from high-resolution radar measurements. J Geophys Res Oceans Atmos 75:3523-3536. doi:10.1029/JC075i018p03523

Gossard EE, Hooke WH (1975) Waves in the atmosphere. Elsevier, New York, 456 pp 
Gur'yanov AE, Kallistratova MA, Martvel FE, Pequr MS, Petenko IV, Time NS (1987) Comparision of sodar and microfluctuation measurements of the temperature structure parameter in mountainous terrain. IzV Atmos Ocean Phys 23:685-691

Holtslag AAM, Svensson G, Baas P, Basu S, Beare B, Beljaars ACM, Bosveld FC, Cuxart J, Lindvall J, Steeneveld GJ, Tjernström M, Van De Wiel BJH (2013) Stable atmospheric boundary layers and diurnal cycles: challenges for weather and climate models. Bull Am Meteorol Soc 94:1691-1706

Kallistratova MA (1962) Experimental investigation of sound wave scattering in the atmosphere. Tr Akad Nauk SSSR, Inst Fiz Atmos 4:203-256 (USAF FTD translation TT-63-441)

King JC, Argentini S, Anderson PS (2006) Contrasts between the summertime surface energy balance and boundary layer structure at Dome C and Halley stations, Antarctica. J Geophys Res 111:D02105. doi:10. 1029/2005JD006130

Kohsiek W (1982) Measuring $\mathrm{C}_{T}^{2}, \mathrm{C}_{Q}^{2}$ and $\mathrm{C}_{T Q}$ in the unstable surface layer and the relations to the vertical fluxes of heat and moisture. Boundary-Layer Meteorol 24:89-107

Kouznetsov RD (2009) The summertime ABL structure over an Antarctic oasis with a vertical Doppler sodar. Meteorol Zeit 18(2):163-167

Kouznetsov R, Lyulyukin V (2014) Kelvin-Helmholtz billows at katabatic winds in Antarctic. In: 17th international symposium for the advancement of boundary-layer remote sensing (ISARS2014), 28-31 Jan, Auckland, NZ (poster 15)

Lyulyukin V, Kouznetsov R, Kallistratova M (2013) The composite shape and structure of braid patterns in Kelvin-Helmholtz billows observed with a sodar. J Atmos Ocean Technol 30:2704-2711

Lyulyukin VS, Kallistratova MA, Kouznetsov RD, Kuznetsov DD, Chunchuzov IP, Chirokova GYu (2015) Internal gravity-shear waves in the atmospheric boundary layer by the acoustic remote sensing data. Izvestia, Atmos Ocean Phys 51(2):193-202

Mahrt L (1998) Stratified atmospheric boundary layers and breakdown of models. Theor Comput Fluid Dyn 11:263-279

McGrath-Spangler EL, Molod A, Ott LE, Pawson S (2015) Impact of planetary boundary layer turbulence on model climate and tracer transport. Atmos Chem Phys 15:7269-7286. doi:10.5194/acp-15-7269-2015

Neff W, Helmig D, Grachev A, Davis D (2008) A study of boundary layer behavior associated with high NO concentrations at the South Pole using a minisodar, tethered balloon, and sonic anemometer. Atmos Environ 42(12):2762-2779

Patterson MD, Caulfield CP, McElwaine JN, Dalziel SB (2006) Time-dependent mixing in stratified KelvinHelmholtz billows: experimental observations. Geophys Res Lett 33:L15608

Petenko I, Pietroni I, Casasanta G, Argentini S, Viola A, Mastrantonio G (2013) Thermal turbulence in the very stable boundary layer: sodar observations at Dome C, Antarctica. Geophysical Research Abstracts, V.15, EGU2013-9442, EGU General Assembly, Austria, Vienna, April 2013

Petenko I, Argentini S, Pietroni I, Viola A, Mastrantonio G, Casasanta G, Aristidi E, Bouchez G, Agabi A, Bondoux E (2014a) Observations of optically active turbulence in the planetary boundary layer by sodar at the Concordia astronomical observatory, Dome C, Antarctica. Astron Astrophys 568:A44. doi:10. 1051/0004-6361/201323299

Petenko I, Mastrantonio G, Argentini S, Pietroni I, Viola A (2014b) Some statistics of the temperature structure parameter in the convective boundary layer observed by sodar. Boundary-Layer Meteorol 150(2):215233. doi:10.1007/s10546-013-9867-1

Pietroni I, Argentini S, Petenko I, Sozzi R (2012) Measurements and parametrizations of the atmospheric boundary-layer height at Dome C, Antarctica. Boundary-Layer Meteorol 143(1):189-206

Pietroni I, Argentini S, Petenko I (2014) One year of surface-based temperature inversions at Dome C, Antarctica. Boundary-Layer Meteorol 150:131-151. doi:10.1007/s10546-013-9861-7

Readings CJ, Colton E, Browning KA (1973) Fine-scale structure and mixing within an inversion. BoundaryLayer Meteorol 4:275

Scorer RS (1969) Billow mechanics. Radio Sci 4(12):1299-1308

Taconet O, Weill A (1983) Convective plumes in the atmospheric boundary layer as observed with an acoustic Doppler sodar. Boundary-Layer Meteorol 25:143-158

Tatarskii VI (1971) The effects of the turbulent atmosphere on wave propagation. Israel Program for Scientific Translations, Jerusalem, $472 \mathrm{pp}$

Venkatesh TN, Mathew J, Nanjundiah RS (2014) Secondary instability as a possible mechanism for clear-air turbulence: a case study. Meteorol Atmos Phys 126:139-160

Weill A, Klapisz C, Strauss B, Baudin F, Jaupart C, Van Grunderbeeck P, Goutorbe JP (1980) Measuring heat flux and structure functions of temperature fluctuations with an acoustic Doppler sodar. J Appl Meteorol 19:199-205

Welch PD (1967) The use of fast Fourier transform for the estimation of power spectra: a method based on time averaging over short, modified periodograms. IEEE Trans Audio Electroacoust AU-15:70-73 
Wood CR, Kouznetsov RD, Gierens R, Nordbo A, Järvi L, Kallistratova MA, Kukkonen J (2013) On the temperature structure parameter and sensible heat flux over Helsinki from sonic anemometry and scintillometry. J Atmos Ocean Technol 30:1604-1615. doi:10.1175/JTECH-D-12-00209.1

Zilitinkevich SS, Esau IN (2003) The effect of baroclinicity on the depth of neutral and stable planetary boundary layers. Q J R Meteorol Soc 129:3339-3356 